\title{
RESPUESTA A LOS COMENTARIOS DE JOSÉ FÉLIX CATAÑO A SENTIMIENTOS Y RACIONALIDAD EN ECONOMIA
}

Jorge Iván Gonzáleza

L os comentarios de Cataño me permiten precisar algunas de las ideas planteadas en Sentimientos y racionalidad en economía ( $R E$ ). Comienzo por agradecerle su juiciosa lectura.

En su presentación inicial toca dos puntos. El primero se refiere a lo que llama "el abandono" de la hipótesis del homo economicus (HE). $\mathrm{Y}$ el segundo al significado y los alcances de los supuestos en los modelos económicos, íntimamente relacionado con el primero. En $S R E$ argumento que una vez se precisan los supuestos del modelo (información perfecta, arbitraje, precios flexibles, etc.) la pieza que falta en el rompecabezas es el sujeto. Y cuando se introduce, no tiene ningún margen de maniobra. Los resultados de su comportamiento son inevitables. Por ello, sería lo mismo que tal individuo fuese un hombre, una mujer, un niño o, incluso, una rata. Todos actuarían de la misma manera. En la literatura a esta última pieza del rompecabezas, que es absolutamente marginal, se la denomina con el ampuloso nombre de homo economicus. Para Sen (1977) el individuo compatible con los supuestos del modelo no es más que un “tonto racional”.

* DOI: https://doi.org/10.18601/01245996.v21n41.12. Recepción: 08-012019, modificación final: 25-03-2019, aceptación: 14-05-2019. Sugerencia de citación: González, J. I. (2019). Respuesta a los comentarios de José Félix Cataño a Sentimientos y racionalidad en economia. Revista de Economía Institucional, 21(41), 275-283.

a Profesor Universidad Externado, [jorgeivangonzalez29@gmail.com], [https://orcid.org/0000-0002-0915-4087]. 
Mientras que en mi presentación el $\mathrm{HE}$ apenas es un añadido, en la visión de Cataño es una pieza central de lo que él llama pensamiento “neoclásico". Habría, entonces, una divergencia fundamental. Desde mi perspectiva, en los modelos, que son una construcción imaginaria, el sujeto ocupa un lugar muy marginal. En la concepción de Cataño, por el contrario, el individuo racional es central en la modelación. Y esta apreciación tiene mucho que ver con el papel que le atribuye al individualismo metodológico, como punto de partida para analizar la sociedad. Si los autores neoclásicos, continúa Cataño, fundamentan su reflexión en el individualismo metodológico, es lógico que el sujeto racional ocupe un lugar medular en los modelos. Esta apreciación es equivocada, ya que del individualismo metodológico no se desprende una supuesta centralidad del sujeto en los modelos. Es cierto que las corrientes no marxistas minimizan el impacto de las relaciones sociales sobre el individuo, y dejan al sujeto un margen de maniobra significativo. Pero de allí no se puede concluir que el sujeto racional sea relevante en los modelos. Lo uno no tiene nada que ver con lo otro. El pensamiento liberal pone en primer lugar la decisión individual, pero en las construcciones imaginarias el agente que decide puede ocupar un lugar muy secundario.

Cataño desprecia el significado de la "construcción imaginaria". La categoría no le parece relevante. En La acción humana, von Mises (1949) explica el significado de la construcción imaginaria. Es un ejercicio lógico, que corresponde al mundo de lo formal-racional. Los modelos no son más o menos realistas. Su función lógica va más allá de la realidad material-empírica. Los modelos son intrínsecamente imaginarios. Y allí no hay espacio para ningún nivel de realismo. En el texto de Cataño pareciera como si unos modelos fueran más realistas que los otros. Ninguno es realista.

E1 modelo, como construcción imaginaria, admite infinidad de supuestos. Y estos se pueden elaborar de tal manera que dejen más o menos espacio para que quepan diversos tipos de sujeto. En las versiones extremas, como en la de Arrow y Debreu (1954), la interacción de precios y cantidades no deja espacio para el sujeto. Y así lo reconoce el mismo Arrow (1986). Para garantizar la consistencia del modelo, es innecesaria la presencia de un sujeto autónomo. Y el individuo no puede actuar de acuerdo con su voluntad, porque la rigidez de los supuestos lleva a que el comportamiento sea único, independientemente de las características de cada persona.

Arrow y Debreu utilizan la categoría "economía abstracta" y muestran las condiciones de posibilidad del equilibrio en ese tipo 
de economía. Reconocen que el modelo, cualquiera que sea, solo es concebible como abstracción. Para ellos es evidente que el modelo de equilibrio no pretende ser realista. Es una construcción imaginaria, que se desarrolla en el campo de lo formal-racional. No se entiende la angustia de Cataño por criticar la falta de realismo a un modelo que nunca se elaboró con la pretensión de explicar el mundo real. Y, precisamente, su fortaleza analítica y su permanencia en el tiempo se deben a que no es realista. El realismo del modelo va en contra de su permanencia en el tiempo. Si la realidad está en continuo cambio, ningún modelo puede ser realista.

A medida que se flexibilizan los supuestos del modelo queda más espacio para introducir diversas modalidades de la racionalidad limitada. Cuando los supuestos se relajan el sujeto gana relevancia. Pero ello no significa -como piensa Cataño- que el modelo sea más realista. Sigue siendo imaginario. Se sigue moviendo en el campo de la economía abstracta. En la visión keynesiana, los humanos que se mueven guiados por "espíritus animales" también pertenecen al mundo de la construcción imaginaria. Cataño dice que para mí el agente keynesiano sería "real" y no "imaginario". No! Esta interpretación es errónea. En tanto construcción imaginaria el mundo keynesiano tampoco es realista. Obsérvese, por ejemplo, la definición de tasa de interés que adopta Keynes:

La tasa monetaria de interés - permítasenos recordar al lector- no es otra cosa que el por ciento de excedente de una suma de dinero contratada para entrega futura, por ejemplo, a un año de plazo, sobre lo que podemos llamar el precio inmediato (spot) o efectivo de esa suma (Keynes 1936, p. 198).

Esta aseveración, que compara el precio futuro del bien con su precio actual no tiene nada de realista. Es imposible demostrar, en el terreno empírico-material, su validez fáctica. El modelo keynesiano, como cualquier otro, también es imaginario. Cataño sí cae en la trampa de pensar que mientras los neoclásicos no dan cuenta de la realidad, él, junto con sus colegas Benetti y Cartelier, sí pueden hacerlo.

Nunca he afirmado que cuando se introducen sujetos con pasiones y sentimientos el modelo es "más realista". Siempre es imaginario. $\mathrm{Ca}$ taño distorsiona el significado de la construcción imaginaria, porque en ningún momento le presta la atención que merece. No comparto su afirmación:

Es normal entonces que leyendo el texto de González salgamos convencidos de que afortunadamente los grandes teóricos de la economía se han acercado a otras ciencias sociales e incorporado una imagen más "realis- 
ta” del agente en sus análisis económicos y sociales, y que la hipótesis del HE hace parte de los conceptos relegados por el progreso científico de los economistas.

La construcción imaginaria es intrínsecamente legítima, independientemente de que el personaje central sea racional o actúe siguiendo sus pasiones animales.

Al explicar el modelo de equilibrio general, siguiendo a Benetti y Cartelier, Cataño pone en primer lugar el sujeto racional. Y lo considera el eje central. En su opinión, el HE es la "hipótesis inicial del análisis económico tradicional”. Y esta posición contradice claramente la que defiendo en SRE. Lo esencial del modelo Arrow-Debreu no es el sujeto sino los supuestos contextuales. E1 HE es una derivación inevitable. O en forma más enfática, es un añadido totalmente secundario.

Además, se equivoca al examinar el proceso que lleva al equilibrio en Arrow-Debreu. No es un subastador que anuncia precios a sujetos racionales. Ese proceso no existe. Arrow y Debreu suponen la existencia del equilibrio, independientemente de la voluntad de los agentes. El equilibrio y la armonización entre sujetos están dados. En sus palabras:

Por consiguiente, una economía abstracta se puede caracterizar por una generalización de un juego en el cual la acción que elige un agente afecta tanto el pago como el dominio de acción de los otros agentes (Arrow y Debreu, 1954, p. 273).

Es claro, entonces, que la armonización de las acciones individuales que permite el equilibrio competitivo no es fruto de ejercicios racionales. Es un supuesto. No es cierto, como dice Cataño, que en el modelo Arrow-Debreu, "se introduce la poderosa figura del subastador que transmite la información de precios a los agentes, recibe sus respuestas y anuncia el momento del equilibrio". Este extraño personaje que actúa a través de propuestas y contrapropuestas no existe. E1 "poderoso deux ex machina" no está presente en Arrow y Debreu. Además, no es necesario, porque en su modelo, en su economía abstracta, la armonización entre compradores y vendedores es un postulado $a$ priori. Es curioso que Cataño introduzca relaciones dinámicas en un modelo esencialmente estático. El equilibrio de Nash del modelo Arrow-Debreu no resulta de ires y venires de los agentes mediados por un subastador. Esta lectura es incorrecta. El equilibrio está dado. Y en la economía abstracta de Arrow-Debreu, la decisión que toma cada agente tiene en cuenta la elección de los otros agentes. Y, de nuevo, insisto en que este resultado es a priori. Por tanto, no importa caracterizar la mayor o menor racionalidad del agente. 
También se equivoca al afirmar que el proceso termina "cuando los individuos saben que están en equilibrio". En Arrow-Debreu los individuos no aprenden. Cataño dice, además, que el modelo Arrow-Debreu "representa un mundo centralizado y autocrático y no un mundo abstracto de comerciantes libres". Tampoco es cierto. E1 equilibrio de Nash, que está presente en Arrow-Debreu, es el de una economía descentralizada. En ninguna parte del modelo se hacen consideraciones sobre la libertad de los sujetos. No es el objeto del artículo. Otros textos de Arrow, comenzando por Social choices and individual values (Arrow, 1951), sí analizan de manera explícita el problema de la libertad individual. Y al llevar hasta sus últimas consecuencias -también en un modelo- la paradoja de Condorcet, concluye que desde el punto de vista lógico no es posible conciliar las preferencias individuales con las colectivas. Pero en Arrow y Debreu el problema no es la libertad de individuo, sino la definición de las condiciones de posibilidad del equilibrio competitivo.

Cataño dice que me confundo en mi lectura de Arrow-Debreu. La confusión es suya. Dice que "el resultado colectivo no depende de cómo se comportan individualmente los agentes, sino de la forma que toman los agregados". La frase parece contradecir sus apreciaciones anteriores sobre la libertad de los agentes, y sobre el conocimiento que tienen del momento en que la economía está en equilibrio.

También dice que "la hipótesis del HE solo es esencial para probar que un equilibrio económico es un óptimo de Pareto". No comparto esta afirmación. El primer teorema del bienestar también corresponde a una economía abstracta, y si se quisiera caracterizar al sujeto de este primer teorema tendríamos que concluir con Sen (1970) que es "imposible" un "liberal paretiano". En otras palabras, el sujeto del primer teorema del bienestar no puede existir. O es liberal o es paretiano. No puede ser lo uno y lo otro. Si es liberal radical no tiene presente al otro, así que no es paretiano. Y si es paretiano, y acepta las limitaciones que impone el otro, no puede ser liberal.

Cataño se aterra porque aún no se ha declarado "muerto" el modelo Arrow-Debreu. O, por lo menos, porque todavía no se lo ha calificado de "inútil". Pero no es necesario matarlo porque nunca ha estado vivo. Es una construcción imaginaria. $\mathrm{Y}$ su fuerza radica en que hoy, 66 años después, sigue siendo una obsesión de Cataño y que, además, nos permite tener este diálogo. Por ello no dudo en calificar esta construcción imaginaria como "maravillosa". La vigencia de un modelo no radica en su realismo, sino en su capacidad para estimular la conversación y el debate. 
Sin duda, los aportes de la "economía del comportamiento" ponen en primer plano la complejidad de los individuos en su interacción en sociedad. En sus modelos el sujeto es central, no un añadido marginal. Y pasan a segundo plano las relaciones de los precios y de las cantidades. En las nuevas construcciones imaginarias el homo socialis ocupa un lugar central. Los supuestos de los modelos se flexibilizan y los sentimientos y la pasión humana son explícitos.

Dice Cataño que estos aportes obligan a renunciar al individualismo metodológico, y a acercarse a Marx. Tampoco comparto esta apreciación. Una visión como la de Commons (1934), que introduce la categoría de "persona institucionalizada" no requiere renunciar al individualismo metodológico. Más aún, cualquier análisis que considere seriamente al sujeto, no puede dejar de lado el individualismo metodológico.

Tampoco hay que renunciar al modelo Arrow-Debreu. Ya decía que numerosos trabajos de Arrow ponen en primer plano la complejidad de los sujetos, y los conflictos derivados de la pasión humana. Y esos análisis, que no consideran la sociedad como un equilibrio armonioso, corresponden a un campo de reflexión diferente al de los modelos de equilibrio. Autores como Arrow van de un lado al otro sin que ello sea inconsecuencia o falta de consistencia. Además, escritos como Social choice and individual values, que nada tienen que ver con los modelos de equilibrio, y que implican interacciones con el otro, no obligan a renunciar al individualismo metodológico. Son construcciones diferentes imaginarias que obedecen a propósitos específicos. Las construcciones imaginarias no son dogmas sino formas abstractas que ayudan a pensar problemas, y a tomar decisiones de política pública. Sin duda, de cada forma de mirar el mundo se derivan resultados de política económica que son relevantes.

Tiene razón Cataño al destacar los "mecanismos de coordinación". La teoría dio un paso importante al no considerarlos dados, e intentar entenderlos. Es la búsqueda del institucionalismo, y de autores que se centran en el diseño de mecanismos, como Hurwicz y Reiter (2006). Ellos reconocen que el mercado se queda corto y que se deben buscar otras formas institucionales que permitan una mejor interacción entre los sujetos.

En las últimas páginas de su reflexión, Cataño introduce la discusión sobre la validación de la teoría económica. El primer comentario es sobre la teoría keynesiana. En mi opinión es una teoría fundada en el desequilibrio. Al rescatar la incertidumbre frente al futuro, y la relevancia de los espíritus animales, el imaginario resultante es de desequilibrio. Para Keynes la incertidumbre es una pieza central del 
análisis, y enmarca su estudio de la moneda, de la tasa de interés y, en general, de las decisiones de inversión y consumo. Cataño recorta el debate y lo reduce al problema de precios fijos o flexibles. Y lo estrecha aún más al decir que la economía keynesiana es "walrasiana”. En vez de adentrarse en la complejidad de los autores, insiste en clasificar y encajonar el debate en taxonomías simplistas. El problema central de Keynes no es rigidez o flexibilidad de precios, sino el de seres humanos que deben actuar sin conocer el futuro. Y como todo es volátil, toda decisión que tomen lleva al desequilibrio. Poco importa que en cierta coyuntura los precios sean flexibles.

La incertidumbre keynesiana tiene que ver de cerca con la forma como los individuos expresan su percepción del futuro a través de la demanda de dinero. Cataño retoma mi frase: "la demanda de dinero es volátil como el comportamiento de las personas". Y esta es una idea central de Keynes. De manera abusiva, Cataño dice que este enfoque es equivalente al del "modelo monetario neoclásico de generaciones traslapadas". No son comparables. Por ejemplo, en la versión del modelo de generaciones traslapadas de Barro (1974), es muy claro que el futuro se introduce en condiciones de estado estacionario. Y gracias a este supuesto se garantiza el equilibrio de largo plazo. Los individuos imaginados por Barro están guiados por expectativas racionales. Keynes jamás aceptaría eliminar los ciclos y la incertidumbre propios de la dinámica. Barro congela el tiempo gracias al equilibrio del estado estacionario, y hace una magistral aplicación del "principio de correspondencia" de Samuelson (1947). En la construcción imaginaria propia de los modelos de generaciones traslapadas la dimensión temporal se pierde. Con justa razón, Hicks (1989) dice que tales aproximaciones no son dinámicas.

Entre las numerosas construcciones imaginarias, las comunidades científicas y los gobiernos van eligiendo según diversos factores. Destaco dos: la capacidad intrínseca del modelo para construir un relato atractivo, y su aceptación por los grupos de poder (académicos y políticos). Ambos están relacionados. Cataño desconoce que detrás de las propuestas de Smith, Marx, Walras, Arrow, Hicks, Keynes, etc., existen grupos de poder que le dan relevancia a estas construcciones imaginarias. Las que, de nuevo, no dudo en calificar de "maravillosas". No entiendo por qué duda del poder político asociado a Marx o a Keynes. Basta recordar la fuerza del Manifiesto del Partido Comunista, o la relevancia política del keynesianismo de la segunda posguerra. La figura de Keynes fue relevante en las negociaciones posteriores a las dos guerras. Su presencia en Bretton Woods fue destacada. 
Por último, Cataño termina poniendo en tela de juicio mi referencia al enfoque marxista que lleva a concluir que el ser social determina la conciencia. Cataño, que a lo largo de su comentario se opone radicalmente al individualismo metodológico, ahora me acusa de "hacer aparecer al marxismo como una teoría donde la sociedad aplasta al sujeto". No llevo el argumento a ese extremo. Muestro que en la perspectiva marxista, el ser social sí tiene una incidencia notable en la forma como la persona se concibe a sí misma y a la sociedad. Esta afirmación sobre la importancia de lo social es más fuerte en Marx que en autores como Commons, para quien lo social apenas es un condicionante de la acción individual.

La manera como la sociedad determina al sujeto depende de numerosos factores, sociales, económicos y culturales. Y los énfasis cambian en forma significativa según se trate de Marx, o de Stalin. Su concepción de la manera como lo social determina la concepción es diametralmente distinta. En SRE comparo la visión de Marx con la de liberales como von Mises. Mientras que Marx pone el acento en los determinantes sociales, von Mises hace énfasis en la iniciativa individual. Entre ambos está Commons. En cualquier caso, advierto, los autores reconocen que siempre hay una interacción entre la sociedad y el sujeto.

$\mathrm{Y}$ para concluir, me diferencio de Cataño en un aspecto que considero central. No estoy preocupado por las escuelas ni por las taxonomías. Prefiero tratar de entender al autor. Él, en cambio, se afana por clasificar y agrupar. Cree tener clara la distinción entre “clásicos”, “neoclásicos”, “marxistas”, "ricardianos”, “sraffianos”, "keynesianos", "poskeynesianos”, “monetaristas”, “institucionalistas”, etc. No me parece importante trazar fronteras porque estoy convencido de que dentro de cada una de esas corrientes, suponiendo que se puedan diferenciar, hay autores excepcionales que han propuesto construcciones imaginarias, que por su fuerza y consistencia interna son atractivas y capaces de desencadenar discusiones económicas y visiones alternativas del mundo.

Y le recuerdo que no solo me parece maravilloso el modelo de equilibrio general de Arrow y Debreu. No oculto mi admiración por otras construcciones imaginarias que menciono en $S R E$. Dentro de nueve años celebraremos un siglo de esa obra maestra elaborada por Cobb y Douglas (1928). Este mundo imaginario, absolutamente platónico, en el que el rendimiento decreciente del factor es compatible con la homogeneidad de grado uno de la función, sigue siendo la base de los modelos de crecimiento, y se reproduce sin cesar en los libros de 
texto, y en los informes de política económica de los gobiernos. Como lo reconocen Cobb y Douglas, su función está lejos de ser una réplica del mundo real. Y una de las razones de su falta de realismo es haber desconocido el papel de los recursos naturales en la producción del acervo de capital y de los demás bienes. Gracias a esta construcción imaginaria se han creado numerosos modelos, estáticos y dinámicos, y la teoría ha introducido categorías tan sorprendentes como la "regla de oro", la "regla de oro modificada" o el "teorema de la autopista". Son fantasías deslumbrantes que nos permiten conversar y tratar de entender la complejidad del mundo. Pobres de aquellos colegas que piensan que estos modelos representan la realidad. Y aún más quienes en su cándida visión de la ciencia, los consideran instrumentos técnicos, desprovistos de juicios de valor.

\section{REFERENCIAS BIBLIOGRÁFICAS}

Arrow, K. (1951). Social choice and individual values. New York: Wiley, 1963, pp. 1-91.

Arrow, K. (1986). Rationality of self and others in an economic system. Journal of Business, 59(4), 385-399.

Arrow, K. y Debreu, G. (1954). Existence of an equilibrium for a competitive economy, Econometrica, 22(3), 265-290.

Barro, R. (1974). Are government bonds net wealth?, Journal of Political Economy, 82(6), 1095-1117.

Cobb, C. y Douglas, P. (1928). A theory of production. American Economic Review, 18(2), 139-165.

Commons, J. (1934). Institutional economics. Its place in political economy, 2 vol. New Brunswick: Transactions Publishers, 1990.

Hicks, J. (1989). Métodos de economía dinámica [1985]. México D.F.: Fondo de Cultura Económica.

Hurwicz, L. y Reiter, S. (2006). Designing economic mechanism. Cambridge: Cambridge University Press.

Keynes, J. M. (1936). Teoría general de la ocupación, el interés y el dinero. México D.F.: Fondo de Cultura Económica, 1976.

Mises, L. von. (1960). La acción humana. Tratado de economía, [1949], 2 vol. Valencia: Fundación Ignacio Villalonga,.

Samuelson, P. (1947). Foundations of economic analysis. Cambridge: Harvard University Press, 1983.

Sen, A. (1970). The impossibility of a Paretian Liberal". Journal of Political Economy, 78(1), 152-157.

Sen A. (1977). Rational fools: A critique of the behavioral foundations of economic theory. Philosophy and Public Affairs, 6(4), 317-344. 